\title{
UM SALVE PELA RECUPERAÇÃO FINANCEIRA DO ESTADO DO RIO DE JANEIRO!
}

Coluna publicada em 27.6.2017: <https://www.conjur.com.br/2017-jun-27/ contas-vista-salve-recuperacao-financeira-estado-rio-janeiro $>$

O Estado do Rio de Janeiro, ao que parece, está falido. ${ }^{1}$ Isso expõe um dos graves problemas de nosso federalismo fiscal, e de difícil solução, que cabe ao Direito Financeiro e às finanças públicas oferecer caminhos para resolver: a insolvência de entes da federação.

Nossa cultura não admite a possibilidade de "falência" de um ente federado. Imaginem vocês se isso levasse à extinção do Estado do Rio de Janeiro. O que significaria, objetivamente? Não vão desaparecer o Pão de Açúcar, o Cristo Redentor, nem as maravilhosas praias fluminenses. Seria incorporado a São Paulo? Não sou capaz de imaginar como seria. Fazer os cariocas substituírem seu simpático sotaque pelo meu da Mooca, o Flamengo se incorporar ao Juventus, substituir a camisa rubro-negra por uma grená-negra, ou ao Corinthians (bom, pelo menos teríamos a maior torcida do planeta) ou ainda ao Palmeiras (resolveria o problema do Mundial?), nem o Vasco à Ponte Preta (ao menos evitaria ter de trocar as camisas). Vinícius de Moraes e Tom Jobim passariam a tecer loas à Garota do Boqueirão, e não à de Ipanema? Pouco provável. Teremos de pôr ketchup na pizza? (Socorro!) Nem incorporá-lo a Minas Gerais. Importaria em transferir os desfiles das escolas de samba para Belo Horizonte? Trocar o chope por leite? Comer pão de queijo na praia? Nem pensar... Brincadeiras à parte, é inimaginável para nossa cultura admitir a extinção de um ente federado. Sendo assim, o que fazer?

\footnotetext{
A tal ponto que o Presidente da Assembleia Legislativa acredita ser a intervenção federal ou o impeachment a única solução: Presidente da ALERJ diz que solução para o RJ é intervenção federal ou impeachment do governador (Globo.com, 22 de junho de 2017).
} 
A questão da relação entre a dívida pública e o federalismo fiscal, embora ainda pouco explorada, cada vez mais se mostra de extrema relevância para a higidez de nossas finanças públicas. $\mathrm{O}$ descontrole das contas públicas em âmbito subnacional já há muito tem sido fonte dos graves problemas financeiros que afetam nosso país e impedem o equilíbrio e sustentabilidade das contas públicas, pois o ente central acaba se vendo obrigado a socorrer os entes subnacionais em apuros (o que ocorreu por diversas vezes no Brasil). ${ }^{2}$

É previsível a ocorrência de problemas financeiros nos entes federados, até mesmo por alteraçóes cíclicas na economia, muitas vezes decorrentes de problemas que fogem ao controle do gestor. No caso do Rio de Janeiro, a queda repentina e significativa das receitas oriundas dos royalties certamente colaborou para as dificuldades financeiras ora enfrentadas. Anos atrás, políticas públicas federais, como a desoneração pela redução do Imposto sobre Produtos Industrializados - IPI com o objetivo de contornar a crise financeira, provocaram a queda nas transferências do Fundo de Participação dos Municípios - FPM e consequente crise financeira nos municípios que dependiam fortemente dessas receitas. Uma demonstração de que problemas orçamentários e crises fiscais cíclicas são inevitáveis nos países em que as relações fiscais intergovernamentais estão fortemente presentes em um modelo de organização federativa. ${ }^{3}$

Esse tipo de problema não é novidade, nem uma peculiaridade brasileira. $\mathrm{O}$ direito norte-americano mostra-se mais compreensivo e avançado em relação a essas questões, já as discute há algum tempo, e há inclusive previsão legal para essas hipóteses, como se vê do capítulo 9 do United States Bankruptcy Code, que estabelece regras para a recuperação financeira das municipalities. ${ }^{4}$ Já foi utilizado várias vezes, sendo o caso mais recente e famoso o da cidade de Detroit, em 2013. Há poucos dias, Porto Rico, ilha que é entidade pública norte-americana, decretou

2 Com bem abordado por Cesar Augusto Seijas de Andrade, em $O$ controle do endividamento público e a autonomia dos entes da Federação (Dissertação de mestrado apresentada à Faculdade de Direito da Universidade de São Paulo, 2012, p. 59-68).

3 Veja-se nesse ponto LEVITIN, Adam J. Fiscal Federalism and limits of bankruptcy. In: CONTI-BROWN; SKEEL JR. When States go broke. Cambridge, 2012, p. 216.

4 Definido pela legislação americana como "a political subdivision or public agency or instrumentality of a State” [11 U.S.C. $\$ 101(40)]$. Cf. DE ANGELIS, Michael; TIAN, Xiaowei. United States: Chapter 9 - Municipal bankruptcy - utilizations, avoidance, and impact. In: CANUTO, Otaviano; LIU, Lili (Eds.). Until debt do us part. World Bank, 2013, p. 315. 
falência. ${ }^{5}$ A Alemanha também já se deparou com o problema, com destaque para os casos de Bremen e Berlim. ${ }^{6}$

O Código de Falências norte-americano prevê que, estando demonstrada a insolvência e for impraticável a composição com os credores, o ente poderá requerer os benefícios previstos na legislação, devendo firmar uma declaração pública de insolvência (disclosure statement) e apresentar um plano de ajuste de suas dívidas (plan of debt adjustment), que será submetido à aprovação e acompanhamento pelo Poder Judiciário, em um processo que se assemelha à nossa recuperação judicial de empresas.?

Nossa Lei de Responsabilidade Fiscal teve como um de seus méritos procurar "estancar a sangria" representada pelos endividamentos excessivos dos entes federados que acabavam por sobrecarregar as finanças federais com transferências de recursos para "cobrir o rombo" e sendo onerada ao arcar com garantias de dívidas alheias. Estabeleceu limites rígidos para o endividamento e medidas duras para aqueles que os ultrapassarem, além de medidas preventivas. Mas parece não ter dado o resultado esperado, pois se a legislação fosse cumprida e os sistemas de fiscalização atuassem de forma atenta e rígida, as coisas não poderiam ter chegado a esse ponto.

Diante de nossa aversão à falência de entes federados, que, como já se pode antever, não se mostra viável, até por razões culturais, a única solução plausível é mesmo a de estabelecer regras que permitam a recuperação financeira, até para atender o princípio da continuidade dos serviços públicos.

A reestruturação fiscal pode ser um excelente instrumento para implementar um sistema de disciplina fiscal, pois obriga o gestor a tomar medidas impopulares que não teria condições de fazer em outras circunstâncias, facilitando as negociaçôes com os credores. ${ }^{8}$ Aumentar tributos, cortar gastos, reduzir benefícios fiscais e outras medidas de arrocho financeiro dificilmente são tomadas "voluntariamente" por um político que precisa de apoio da população que o elegeu e poderá voltar a fazê-lo na próxima eleição.

Uma das desvantagens que se costuma apontar em medidas que importam em conceder benefícios a entes superendividados, como é atualmente o caso do

5 Porto Rico pede maior falência pública da história dos EUA ( $O$ Globo, 3 de junho de 2017).

6 STIFFLER, Myles. Fiscal Federalism and insolvency: contrasting cases of the U.S.A. and Germany. CEU-IBEI, 2015. p. 28-35.

7 Sobre esse tema, veja DE ANGELIS; TIAN, op. cit., p. 311-351; e também MATTOS, Eduardo. Bail-out público? Falência, Direito \& Economia e a experiência americana (site JOTA, 20 de janeiro de 2017).

8 LEVITIN, op. cit., p. 224-227. 
Rio de Janeiro e outros entes da federação, é o chamado "risco moral" (moral hazard). Aqueles que se comportaram adequadamente, foram gestores responsáveis e fizeram os sacrifícios no tempo e forma devidos, agora se veem na condição de arcar com o ônus de dividir as despesas com aqueles menos diligentes e responsáveis. Mas esse risco não é significativo, como demonstra David Skeel. Um Governador de Estado submetido a um processo falimentar estaria sujeito a tantas decisões impopulares e a um prejuízo em sua reputação que dificilmente reconheceria como compensadora uma medida dessa natureza, destaca o autor.?

Como não adianta chorar sobre o leite derramado, nosso ordenamento jurídico, pressionado pela crise financeira, editou recentemente a Lei de Recuperação Fiscal (Lei Complementar 159, de 19.5.2017, "que institui o Regime de Recuperação Fiscal dos Estados e do Distrito Federal”), estabelecendo o regime jurídico aplicável aos entes federados que, estando em dificuldades financeiras, desejem e possam voltar a ter uma atividade financeira sustentável e equilibrada.

Orientado pelos princípios "sustentabilidade econômico-financeira, da equidade intergeracional, da transparência das contas públicas, da confiança nas demonstrações financeiras, da celeridade das decisões e da solidariedade entre os Poderes e os órgãos da administração pública", o Regime de Recuperação Fiscal "envolve a ação planejada, coordenada e transparente de todos os Poderes, órgãos, entidades e fundos dos Estados e do Distrito Federal para corrigir os desvios que afetaram o equilíbrio das contas públicas, por meio da implementação das medidas emergenciais e das reformas institucionais determinadas no Plano de Recuperação elaborado previamente pelo ente federativo que desejar aderir a esse Regime" (LC 159, art. 1º).

Prevê um Plano de Recuperação com a implementação de uma série de medidas voltadas ao equilíbrio das contas públicas (art. $2^{\circ}$ ), o cumprimento das condições estabelecidas pelo art. $3^{\circ}$ da referida lei, e será acompanhado por um Conselho de Supervisão, que será composto por três membros (um indicado pelo Ministério da Fazenda, outro pelo Tribunal de Contas da União e o terceiro pelo Estado em Regime de Recuperação Fiscal - art. 6º). Durante o período de recuperação, o Estado ficará sujeito a uma série de vedações (art. $8^{\circ}$ ) para que possa auferir os benefícios previstos nos artigos $9^{\circ}$ a 11 , entre os quais o de suspender o pagamento da dívida com a União por três anos.

É importante que essa nova lei seja bem aplicada, e para isso precisa ser levada a sério, o que não tem sido a regra no âmbito do Direito Financeiro. ${ }^{10}$

\footnotetext{
9 SKEEL JR., David A. State bankruptcy from the ground up. In: CONTI-BROWN; SKEEL JR. When States go broke. Cambridge, 2012, p. 195-196.

10 A coluna mencionada consta neste livro.
} 
Vê-se que essa lei veio, em um primeiro momento, para ajudar os Estados em situação mais crítica, como Rio de Janeiro, Minas Gerais e Rio Grande do Sul. ${ }^{11}$

Um dos requisitos para aderir ao Regime de Recuperação Fiscal é que as despesas liquidadas com pessoal correspondam a um mínimo de $70 \%$ da RCL (art. 3o, II, LC 159/2017). Uma situação que não deveria ter ocorrido, pois é (ou deveria ser) precedida de uma série de medidas preventivas, como alertas emitidos pelos Tribunais de Contas (art. 59, \$1 $\mathrm{o}$, II, LRF), proibições de conceder aumentos, reajustes, de criar novos cargos, de admitir pessoal, de contratar horas extras (art. 22, parágrafo único, LRF) quando atingir 95\% do limite, multas aplicadas ao Governador, pelos Tribunais de Contas por terem eles deixado de ordenar ou de promover a execução de medidas para a redução do montante da despesa total com pessoal (art. 5, IV, Lei 10.028/2000).

Será que essas medidas foram tomadas? Como foi possível chegar a esse ponto? Veja-se o caso do Rio de Janeiro. Ao final de 2015, em seu Relatório de Gestão Fiscal constava que o consolidado de gastos com pessoal somava cerca de $\mathrm{R} \$ 22$ bilhões, apenas 43,14\% da RCL. ${ }^{12}$ Ao final de 2016, informa que gasta com pessoal cerca de $\mathrm{R} \$ 33$ bilhões, o que equivaleria a 72,31\% da RCL! ${ }^{13}$

Não por acaso, o TCE/RJ ${ }^{14}$ emitiu parecer desfavorável às Contas do Governador carioca referentes ao exercício de $2016 .{ }^{15}$

11 Entra em vigor lei de recuperação fiscal dos Estados (site do Palácio do Planalto, 22 de maio de 2017). Disponível em: <http://www2.planalto.gov.br/acompanhe-planalto/noticias/2017/05/ entra-em-vigor-lei-de-recuperacao-fiscal-dos-estados $>$.

12 Governo do Rio de Janeiro. Relatório de Gestão Fiscal - jan 2015 a dez 2015. <http://www. fazenda.rj.gov.br/sefaz/content/conn/UCMServer/path/Contribution\%20Folders/contadoria/relatoriosContabeis/relat_conta_gestao/2015/Volume\%2005/5.4-RGF3\%C2\%BAQud-Cons/Anexo_1_3\%C2\%B0Quad_RGF_Consolidado_2015.PDF?lve>.

13 Governo do Rio de Janeiro. Relatório de Gestão Fiscal - jan 2016 a dez 2016. <http://www. fazenda.rj.gov.br/cge/content/conn/UCMServer/path/Contribution\%20Folders/contadoria/ relatoriosContabeis/relat_conta_gestao/2016/Volume\%2 004/4.04\%20-\% 20 Relat\%C3\%B3rios\%20de\%20Gest\%C3\%A3oFiscal-\%203\%C2\%BAQuadrimestre\%20-\%20Consolidado/Anexo\%201\%20-\%20Demonstrativo\%20Consolidado\%20da\%20Despesa $\% 20$ com $\% 20$ Pessoal.pdf?lve>.

14 Aliás, importante ressaltar, sem os Conselheiros afastados pela "Operação Quinto do Ouro" - veja-se a coluna Moralização da administração pública: chegou a vez dos Tribunais de Contas, publicada em 4 de abril de 2017 e que consta deste livro.

15 Tribunal de Contas do Estado emite parecer prévio contrário às contas de Governo do Rio de Janeiro referentes ao ano de 2016 (site do TCE/RJ, 30 de maio de 2017). <http://www.tce. rj.gov.br/web/guest/todas-noticias/-/asset_publisher/SPJsTl5LTiyv/content/contas-de-governo-2016-parecer-previo-contrario> 
A que se deve essa repentina mudança? Será que o Rio de Janeiro "maquiava” suas contas e agora passará a admitir ter se excedido nos gastos com pessoal, apenas para entrar no Regime de Recuperação Fiscal? Deu-se um "jeitinho brasileiro" nessa contabilidade? ${ }^{16}$

O carioca Paulo Coelho criou seu Alquimista, famoso no mundo todo, mas certamente não com a intenção de que viesse a agir na contabilidade pública fluminense para transformar dívida em receita...

A situação do Rio de Janeiro é grave. Já decretou "estado de calamidade pública." ${ }^{17}$ Esse nosso Estado tão querido, que já teve de lidar com os sequestros perpetrados pelo Comando Vermelho e outras "instituiçôes não governamentais", agora passou a lidar com os sequestros financeiros comandados pelo Poder Judiciário, que avançam ferozmente sobre os cofres públicos, e foram recentemente obstados por decisão do STF. Os Ministros Alexandre de Moraes e Luís Roberto Barroso destacaram a inviabilidade de gerir as finanças do Estado sob uma verdadeira "corrida maluca" com "guerrilha de liminares", na qual quem chega primeiro leva o dinheiro. ${ }^{18}$

Até o carnaval está ameaçado pelo corte de despesas! ${ }^{19}$

É preciso "dar um jeito" (não brasileiro...) nessa situação, da melhor forma e o quanto antes. O Brasil não pode ficar sem o nosso Rio de Janeiro. Precisamos dele como sempre foi, com sol, samba, sorriso e alegria, e até mesmo um pouco do "jeitinho carioca" (menos o ketchup na pizza, por favor!).

16 Sobre essa questão, veja-se a coluna Contas "maquiadas" não vão tornar nosso país mais bonito, publicada em 12 de fevereiro de 2013 e que consta neste livro.

17 Coluna Crise leva as finanças públicas ao "estado de calamidade", publicada em 28 de junho de 2016 e que consta neste livro.

18 STF, ADPF 405, 14.6.2017; STF suspende decisões que bloqueavam mais de R 1 bi em recursos do RJ (Valor Econômico, 14 de junho de 2017).

19 "A medida é uma resposta radical ao corte de 50\% nos recursos de subvenção anunciado nesta segunda (12) pelo prefeito Marcelo Crivella", diz a notícia "Liga das Escolas de Samba do Rio suspende desfiles do Carnaval 2018” (Portal UOL, 14 de junho de 2017). 